\title{
A Radiographic Assessment of the Prevalence of Pulp Stones in Molars Regarding to the Side
}

\author{
Pavlina Aleksova \\ University Dental Clinical Center "St. Panteleimon"- Department of Restorative dentistry and Endodontics, \\ Faculty of Dentistry, University "Ss. Cyril and Methodius", Skopje, R. of Macedonia
}

\begin{abstract}
Introduction: The prevalence of pulp stones varies, depending on the study type, design and radiographic technique employed. Pulp stones more often occur in molars than in premolars and incisive. The intention of the study is to determine the prevalence of dental pulp stones in molars occurrence in accordance with the side. Materials and Methods: In this study were included random samples 150 patients aged between 20-60 years, or 3108 teeth, 623 has pulp stones. The X-ray assessment of the jaws was being made by subjecting the suspected teeth to the panoramix and retroalveolar X-ray according to Dick. Statistically computer analysis was confirmed to the 425 teeth - molars. Results: The results obtained from the carried out examinations showed that: 248 molars (58.3\%) left side, and 177 molars (41.6\%) - right side, in maxilla and mandible, in both the sexes. With statistically computer analysis was confirmed that the variation is significant i.e. $Z=4.800 ; P=0.000$. Conclusion: From these results can be to conclude that, the prevalence of pulp stones in molars is high of the left side, according with right side. The analyses carried out by making advantage of the radiography showed that greater attention should be paid to the analysis of the $X$-rays, especially to the Panoramix $X$-rays, because they enable detection of the dental calcifications in the asymptomatic teeth regarding the jaws as a whole.
\end{abstract}

Keywords: molars, prevalence, pulp stones, X-rays, panoramic X-rays, the side, statistically computer analysis.

\section{Introduction}

The fact that pulp stones are referred to as being provocateurs of pain with different intensity makes them cause difficulties in diagnosing.

When observed from therapeutic aspect, they appear to be of greater importance because they can make the access to the dental roots difficult or in some cases completely impossible, and they can also be the reason for groundless extraction of a tooth or a group of teeth.

According radiographic analysis of the coronal dental calcifications or dental pulp stones - more often occur with molars - more often with the upper first molars than with the premolars and the incisive teeth [1-6].

Greater percentage of denticles occurs with teeth in the maxilla rather than with the teeth in the mandibula, the exception to which are the incisive teeth which have more often occurrence with the mandibula [1].

\section{Materials and Methods}

In this study were included random samples 150 patients aged between 20-60 years, or 3108 teeth, 623 has pulp stones. The X-ray assessment of the jaws was being made by subjecting the suspected teeth to the panoramix and retroalveolar X-ray according to Dick. Statistically computer analysis was confirmed to the 425 teeth - molars.

The results obtained by application of graphically, roentgenologically and statistically methods.

\section{Results}

Below are the results, shown graphically, roentgenologically and statistically.

Table 1: Prevalence of pulp stones in total teeth of 150 patients, aged $20-60$ years

\begin{tabular}{|c|c|c|c|c|c|c|}
\hline $\begin{array}{c}\text { Total } \\
\text { teeth }\end{array}$ & molars & percent & premolars & percent & incisives & percent \\
\hline $\mathrm{N}$ & $\mathrm{N}$ & $\mathrm{n} \mathrm{( \% )}$ & $\mathrm{N}$ & $\mathrm{n}(\%)$ & $\mathrm{N}$ & $\mathrm{n}(\%)$ \\
\hline 623 & 425 & $68.2 \%$ & 172 & $27.6 \%$ & 26 & $3.2 \%$ \\
\hline
\end{tabular}

Table 1 its presentation of the prevalence of dental calcifications according to the type of teeth.

- Prevalence of dental calcifications in molars is 68.2 per cent

- Prevalence of dental calcifications in premolars is 27.6 per cent and

- Prevalence of dental calcifications in incisive teeth 3.2 per cent

There is a significant difference; denticles in molars have more frequent prevalence compared to the premolars and the incisive teeth.

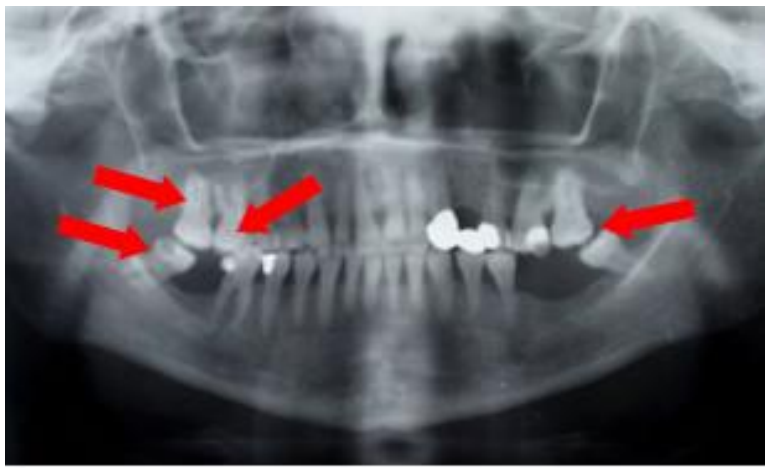

Figure 1: Pulp stones in upper first and second molars, and lower second molar 


\section{International Journal of Science and Research (IJSR) \\ ISSN (Online): 2319-7064}

Index Copernicus Value (2013): 6.14 | Impact Factor (2014): 5.611

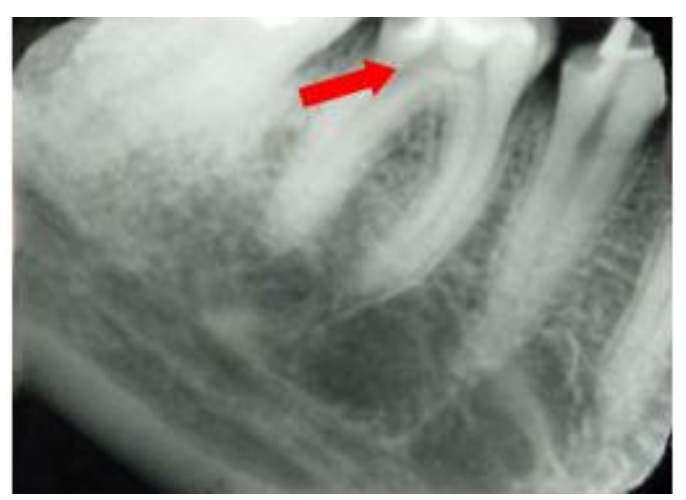

Figure 2: Pulp stone in lower first left molar

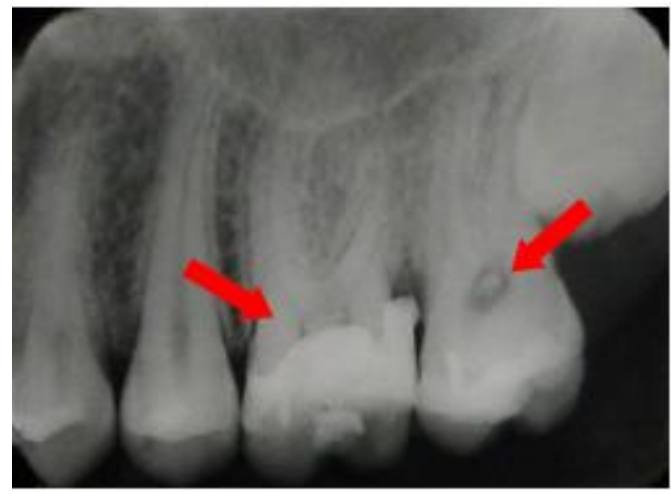

Figure 3: Pulp stones in upper left first and second molar

Regarding the side, pulp stones in the molars show:

From 425 molars with denticles: - 248 molars (58.3\%) - left side, $177(41.6 \%)$ - right side, in maxilla and mandible.

- 328 teeth $(52.6 \%)$ - left side

- 295 teeth $(47.3 \%)$ - right side

\section{--- Comparison of two proportions ---}

- Group $1 \mathrm{n}=42526 \mathrm{p}=0.583$

- Group $2 \mathrm{n}=42526 \mathrm{p}=0.416$

- The variation is: -0.167

- Standard deviation of the variation: 0.0343

- $95 \%$ secure interval in the variation: -0.09977 to 0.2342

$Z=4.800 ; P=0.000$

The variation is significant.

\section{Discussion}

Calcifications in the dental pulp, as a phenomenon with diverse occurrence and manifestation, represent a subject of constant interest not only from the perspective of being a separate dental entity but also because of the fact that they are interesting to observe and deal with from diagnostic and therapeutic aspect.

Through the prism of literature findings there can be concluded that dental calcifications are not prevalent only at certain group of teeth, but pulp stones more often occur in molars than in premolars and incisive.
Kannan S., Kannepady SK., Muthu K., Jeevan MB., Thapasum A., came to a conclusion that pulp stones is found significantly more in molars. There was no significant correlation with sex, increasing age, dental arches, and ethnic races [7].

Molars had statistically more pulp stones than premolars. Pulp stones were significantly more common in the maxilla compared with mandible [8].

Radiographic determination of dental calcifications according to the above mentioned findings enables relevant statistical analysis, presentation of frequency of the distributions in various types of teeth, which largely corresponds to the findings of other authors [9-11].

\section{Conclusion}

The analyses we carried out by making advantage of the radiography showed that greater attention should be paid to the analysis of the X-rays, especially to the Panoramix Xrays, because they enable detection of the dental calcifications in the asymptomatic teeth regarding the jaws as a whole. Insist on this because of the fact that the present clinical image is not very specific, which on its behalf imposes the need for analysis which would be more than just a usual everyday routine method, and also the need for medical observation in order to avoid making oversight of any kind regarding these cases.

\section{References}

[1] P. Aleksova, "Dental calcifications-reason for special analysis" Master's Degree Paper (MD Paper), 1: pp. 6267, 2006.

[2] P. Aleksova, "Prevalence of pulp stones in Molars Regarding the adental Arches". International Journal of Science and Research (IJSR). ISSN (Online): 23197064, Volume 4 Issue 7, p. 3: pp. 1990 - 1993, 2015.

[3] P. Aleksova, "Prevalence of coronal pulp stones in maxillary first and second molars". International Journal of Science and Research (IJSR). ISSN (Online): 23197064, Volume 4 Issue 7, pp. 2476-2478, 2015.

[4] P. Aleksova, "Prevalence of coronal pulp stones in mandibular first and second molars". International Journal of Science and Research (IJSR). ISSN (Online): 2319-7064, Volume 4 Issue 7, pp. 2550-2552, 2015.

[5] P. Aleksova, "A radiographic assessment of the prevalence of pulp stones in premolars regarding the dental arches". International Journal of Science and Research (IJSR). ISSN (Online): 2319-7064. Volume 4,issue 3, Page 5: 2243-2247, 2015.

[6] P. Aleksova, "Prevalence of pulp stones in incisive teeth regarding the dental arches". International Journal of Science and Research (IJSR). ISSN (Online): 23197064. Volume 4,issue 4, Page 7: 3170-3172, 2015.

[7] S. Kannan, SK. Kannepady, K. Muthu, MB. Jeevan, A. Thapasum, "Radiographic Assessment of the Prevalence of Pulp Stones in Malaysians". J. Endod.; Vol. 41(3): pp. 333-7, 2015. 
[8] H. Colak, A. Arif Celebi, M. Mustafa Hamidi, Y. Bayraktar, Tu. Colak and R. Uzgur, "Assessment of the prevalence of pulp stones in a sample of Turkish Central Anatolian population". The Scientific World Journal.2012; Vol.2012, Article ID 804278.

[9] A. Hamasha al-Hadi, A. Darwazeh, "Prevalence of pulp stones in Jordanian adults". Oral Radiology Endodontic, 1998; Dec Vol; 86, pp. 730 - 732.

[10] C. T. Lin, R. T. Roan, W. J. Rou, J. H. Chen, F. H. Chuang, T. Y. Hsieh, "A radiographic Assessment of the Prevalence of Pulp Stones in Taiwanese". Svenska Massan, Vol. 11:pp. 12 - 15, 2003.

[11] Y. Sisman, AM. Aktan, E. Tarim-Ertas, Me. Ciftci, AE. Sekerci, "The prevalence of pulp stones in a Turkish population. A radiographic survey". Medici Oral Pathology, 17: pp. 212-217, 2012. 